\title{
Design and Application of Optimization Software for Substation Operation Mode Based on EMS
}

\author{
Nannan Gao, Jinxin Huang, Hongbo Li \\ State Grid of China Technology College, Jinan, China. \\ Email: gao_nannan@163.com
}

Received March, 2013

\begin{abstract}
This paper proposes a kind of optimization software for substation operation mode, which can not only read data on-line from EMS, but also calculate total loss of substations in parallel operation, split operation or individual operation mode. It can also select the most optimized way and feed the conclusion back to EMS to make substations operate in the most optimized way. The software is suitable for optimization of substation in rural power grid.
\end{abstract}

Keywords: Optimization; Substation Operation Mode; On-line; Closed Loop

\section{Introduction}

The rural power grid is one of the important parts of electric power system. It generally has the character of small-scale, even non-network [1]. Therefore, the emphasis of rural power grid optimization should be laid on substation operation mode. The substation operation mode has a large impact on the loss of rural power grid because of the large variation of load [2]. Accordingly when substations operate in the most optimized way, they can obtain obvious economic benefit.

The present Energy Management System (EMS) has not the function which can optimize the operation mode of substations. So we design a kind of optimization software for substation operation mode on the basis of EMS. It can not only select the most optimized substation operation mode according to the on-line data, but also realize the closed loop controlling which feed the conclusion back to EMS. EMS will regulate the operation mode of substation correspondingly to make it operate in the most optimized way. Moreover, the software also has convenient function of statistic, accumulation, inquiry and print. During the trial running, the software has realized obvious economic benefit.

\section{Design of Software}

The framework of optimization software for substation operation mode is shown in Figure 1. The flowchart of optimization software for substation operation mode is shown in Figure 2.

The software reads data from two parts of EMS through the private data interface. One comes from Power Application Software (PAS) including the topological relation of all the substation equipments and their essential parameter. Another one comes from Supervisory Control and Data Acquisition (SCADA) system including the telemetry date and remote data of substation. All the data will be input in the optimization module of the software.

First the optimization module will judge the connection of all the substation equipments by their topological

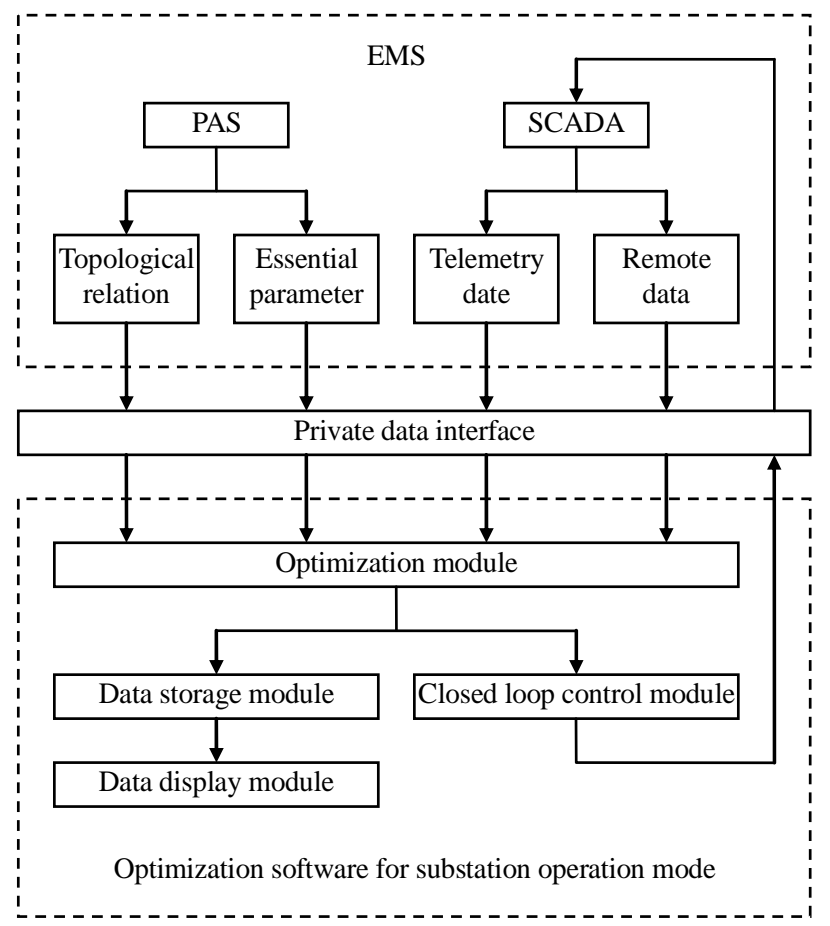

Figure 1. Framework of optimization software for substation operation mode. 


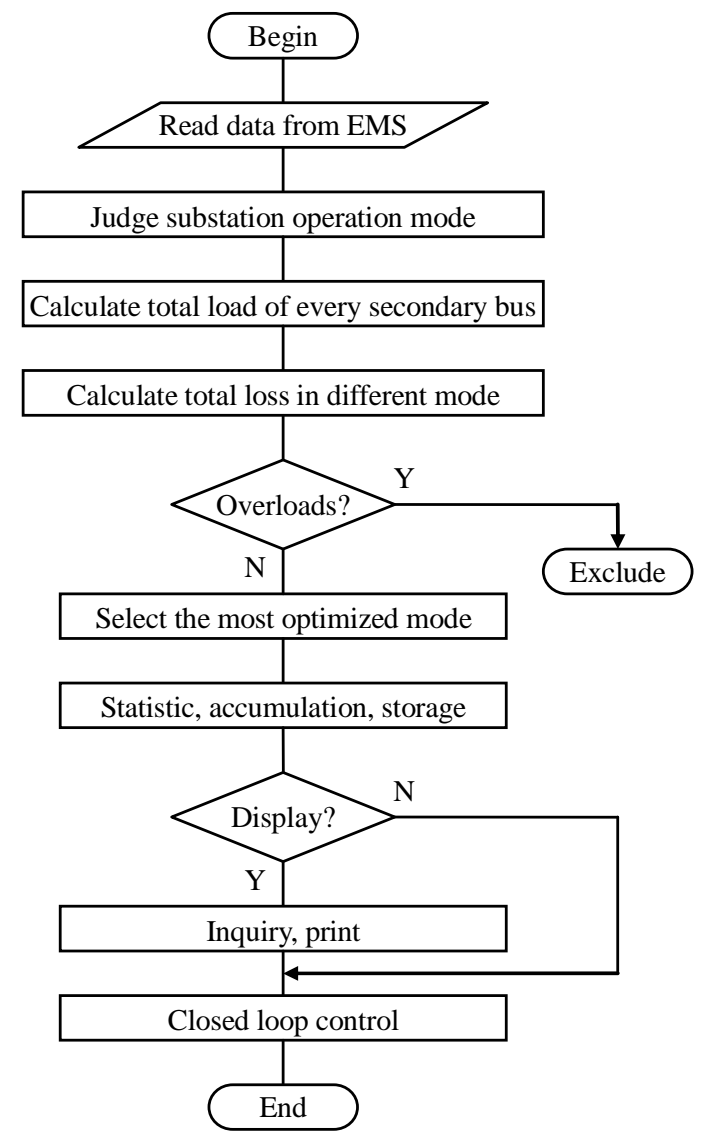

Figure 2. Flowchart of optimization software for substation operation mode.

relation. Then the optimization module will judge the current substation operation mode which is parallel operation, split operation or individual operation by the remote data of substation. And the line which is running in the secondary side will be judged by the same way. After that, the optimization module can calculate the total load of every secondary bus by the telemetry date of substation.

Based on these analyses, the optimization module can calculate the total loss of the substation when it operates in different mode, and select the most optimized way according to the result. In addition, it can also judge whether each transformer overloads in some way of operation. If one transformer overloads in a certain way, the mode would not take part in the underneath preferential selection. The calculation method of total loss when transformer operates in the different mode will be introduced in detail later.

Further more, the optimization module has the function of statistic and accumulation which can calculate the total loss of the substation when it operates in the current mode or the most optimized mode every day, every month, every year, and so on.

The optimization module will put all the result into the data storage module of the software. The data display module of the software will realize the function of inquiry and print by reading data from the data storage module.

At the same time, the optimization module will put the most optimized operation mode into the closed loop control module, which can feed the conclusion back to SCADA system through the private data interface. SCADA system will regulate the operation mode of substation correspondingly to make it operate in the most optimized way.

\section{Algorithm}

The emphasis of a substation's total loss should be laid on its transformers'. Take, for example, a substation which has two transformers and two buses in the secondary side, the software uses following algorithm.

A transformer's total loss consists mainly of iron loss and copper loss [3-4]. Iron loss can be considered as no-load loss because copper loss produced by no-load current can be ignored. In addition, iron loss is decided by the main flux in the iron, and the main flux essentially remains unchanged either no-load or on-load if the applied voltage remains unchanged. Therefore, iron loss can also be considered as no-load loss either no-load or on-load. The calculation method of total loss is shown in equation (1) [5-6].

$$
P_{\text {total loss }}=P_{0}+\frac{S^{2}}{S_{N}^{2}} \times P_{k}
$$

where $P_{0}$ is transformer no-load loss, $S$ is transformer apparent power, $S_{N}$ is transformer capacity, $P_{k}$ is transformer short-circuit loss.

Based on these analyses, the calculation method of total loss in the way of transformer 1 individual operation is as equation (2) shows.

$$
P_{\text {loss } 1}=P_{01}+\frac{\left(P_{1}+P_{2}\right)^{2}+\left(Q_{1}+Q_{2}\right)^{2}}{S_{N 1}^{2}} \times P_{k 1}
$$

where $P_{01}$ is no-load loss of transformer $1, P_{1}$ is active power of bus 1 in the secondary side, $P_{2}$ is active power of bus 2 in the secondary side, $Q_{1}$ is reactive power of bus 1 in the secondary side, $Q_{2}$ is reactive power of bus 2 in the secondary side, $S_{N 1}$ is capacity of transformer 1 , and $P_{k 1}$ is short-circuit loss of transformer 1 .

Similarly, the calculation method of total loss in the way of transformer 2 individual operation is as equation (3) shows.

$$
P_{\text {loss } 2}=P_{02}+\frac{\left(P_{1}+P_{2}\right)^{2}+\left(Q_{1}+Q_{2}\right)^{2}}{S_{N 2}^{2}} \times P_{k 2}
$$

where $P_{02}$ is no-load loss of transformer $2, S_{N 2}$ is capacity of transformer $2, P_{k 2}$ is short-circuit loss of transformer 2 . 
In the same way, the calculation method of total loss in the way of split operation is as equation (4) shows.

$$
P_{\text {loss split }}=P_{01}+P_{02}+\frac{\left(P_{1}^{2}+Q_{1}^{2}\right) P_{k 1}}{S_{N 1}^{2}}+\frac{\left(P_{2}^{2}+Q_{2}^{2}\right) P_{k 2}}{S_{N 2}^{2}}
$$

The calculation method of total loss in the way of parallel operation can be obtained as follow. The relationship of the two transformer apparent power is shown in equation (5) according to the load distribution formula.

$$
\frac{S_{1}}{S_{2}}=\frac{S_{N 1}}{S_{N 2}} \times \frac{u_{k 2}}{u_{k 1}}
$$

where $S_{1}$ is apparent power of transformer $1, S_{2}$ is apparent power of transformer $2, u_{\mathrm{k} 1}$ is impedance voltage of transformer $1, u_{\mathrm{k} 2}$ is impedance voltage of transformer 2 .

The calculation method of the two transformers apparent power can be obtained as shown in equation (6) and (7) based on equation (5).

$$
\begin{aligned}
& S_{1}=\frac{\frac{S_{N 1}}{u_{k 1}}}{\frac{S_{N 1}}{u_{k 1}}+\frac{S_{N 2}}{u_{k 2}}} \times S \\
& S_{2}=\frac{\frac{S_{N 2}}{u_{k 2}}}{\frac{S_{N 1}}{u_{k 1}}+\frac{S_{N 2}}{u_{k 2}}} \times S
\end{aligned}
$$

The calculation method of total loss in the way of parallel operation can be obtained as shown in equation (8) considering equations (1), (6) and (7).

$$
\begin{aligned}
P_{\text {loss parallel }}= & P_{01}+P_{02}+\frac{\left(P_{1}+P_{2}\right)^{2}+\left(Q_{1}+Q_{2}\right)^{2}}{\left(\frac{S_{N 1}}{u_{k 1}}+\frac{S_{N 2}}{u_{k 2}}\right)^{2}} \\
& \times\left(\frac{P_{k 1}}{u_{k 1}^{2}}+\frac{P_{k 2}}{u_{k 2}^{2}}\right)
\end{aligned}
$$

In conclusion, the software can calculate total loss in parallel operation, split operation and individual operation mode by equations (2), (3), (4) and (8).

\section{Example}

The software has been put into operation successfully at the Second Power Supply Bureau of Harbin since last March. During this period, the software has characteristic of stable operation, friendly interaction and easy to use. Further more, the total loss average of all the four substations has dropped to 86.79 percent, which proved the software had obvious economic benefit.

The deference of substations' total loss every month

\begin{tabular}{|c|c|c|c|c|c|}
\hline Time & $\begin{array}{l}\text { Lingbei } \\
\text { Substation }\end{array}$ & $\begin{array}{l}\text { Xuguang } \\
\text { Substation }\end{array}$ & $\begin{array}{l}\text { Qianjin } \\
\text { Substation }\end{array}$ & $\begin{array}{l}\text { Weixing } \\
\text { Substation }\end{array}$ & $\begin{array}{l}\text { Monthly } \\
\text { Average }\end{array}$ \\
\hline March, 2012 & 1425.86 & 1638.45 & 945.16 & 1634.29 & 1410.94 \\
\hline April, 2012 & 1726.94 & 1048.62 & 1824.65 & 942.61 & 1385.71 \\
\hline May, 2012 & 1159.42 & 1726.48 & 1248.26 & 824.95 & 1239.78 \\
\hline June, 2012 & 824.59 & 942.85 & 2045.13 & 1354.92 & 1291.87 \\
\hline July, 2012 & 1752.61 & 1324.58 & 1724.06 & 2049.85 & 1712.78 \\
\hline August, 2012 & 2195.42 & 1098.25 & 814.25 & 1348.64 & 1364.14 \\
\hline September, 2012 & 1628.15 & 824.21 & 1248.65 & 2149.75 & 1462.69 \\
\hline October, 2012 & 975.18 & 1725.14 & 1248.36 & 1579.48 & 1382.04 \\
\hline November, 2012 & 1348.90 & 846.35 & 943.24 & 1736.48 & 1218.74 \\
\hline December, 2012 & 1982.10 & 1345.01 & 1685.95 & 2048.26 & 1765.33 \\
\hline January, 2013 & 1068.26 & 995.42 & 1248.54 & 1647.24 & 1239.87 \\
\hline $\begin{array}{l}\text { Average of each } \\
\text { Substation }\end{array}$ & 1462.49 & 1228.67 & 1361.48 & 1574.22 & 1406.72 \\
\hline
\end{tabular}
between they operate in original mode and in the most optimized way is shown in Table $\mathbf{1 .}$

\begin{tabular}{|c|c|c|c|c|c|}
\hline Time & $\begin{array}{l}\text { Lingbei } \\
\text { Substation }\end{array}$ & $\begin{array}{l}\text { Xuguang } \\
\text { Substation }\end{array}$ & $\begin{array}{l}\text { Qianjin } \\
\text { Substation }\end{array}$ & $\begin{array}{l}\text { Weixing } \\
\text { Substation }\end{array}$ & $\begin{array}{l}\text { Monthly } \\
\text { Average }\end{array}$ \\
\hline March, 2012 & $86.61 \%$ & $84.62 \%$ & $91.13 \%$ & $84.66 \%$ & $86.75 \%$ \\
\hline April, 2012 & $83.79 \%$ & $90.16 \%$ & $82.87 \%$ & $91.15 \%$ & $86.99 \%$ \\
\hline May, 2012 & $89.12 \%$ & $83.79 \%$ & $88.28 \%$ & $92.26 \%$ & $88.36 \%$ \\
\hline June, 2012 & $92.26 \%$ & $91.15 \%$ & $80.80 \%$ & $87.28 \%$ & $87.87 \%$ \\
\hline July, 2012 & $83.55 \%$ & $87.56 \%$ & $83.81 \%$ & $80.76 \%$ & $83.92 \%$ \\
\hline August, 2012 & $79.39 \%$ & $89.69 \%$ & $92.36 \%$ & $87.34 \%$ & $87.19 \%$ \\
\hline September, 2012 & $84.72 \%$ & $92.26 \%$ & $88.28 \%$ & $79.82 \%$ & $86.27 \%$ \\
\hline October, 2012 & $90.85 \%$ & $83.80 \%$ & $88.28 \%$ & $85.17 \%$ & $87.03 \%$ \\
\hline November, 2012 & $87.34 \%$ & $92.05 \%$ & $91.14 \%$ & $83.70 \%$ & $88.56 \%$ \\
\hline December, 2012 & 81.39\% & $87.37 \%$ & $84.17 \%$ & $80.77 \%$ & $83.43 \%$ \\
\hline January, 2013 & $89.97 \%$ & $90.66 \%$ & $88.28 \%$ & $84.54 \%$ & $88.36 \%$ \\
\hline $\begin{array}{l}\text { Average of each } \\
\text { Substation }\end{array}$ & $86.27 \%$ & $88.47 \%$ & $87.22 \%$ & $85.22 \%$ & $86.79 \%$ \\
\hline
\end{tabular}

The percentage of substations' total loss per month has dropped as shown in Table 2.

Table 1. Deference of total loss (kWh).

Table 2. Percentage of total loss has dropped. 


\section{Conclusions}

The optimization software for substation operation mode is suitable for optimization of substation in rural power grid. It can not only read data on-line from EMS, but also calculate total loss of substations when parallel operation, split operation or individual operation, and select the most optimized way, as well as feed the conclusion back to EMS to make substations operate in the most optimized way. The software has obvious economic benefit during the trial operation.

\section{REFERENCES}

[1] X. Q. Wang, "Discussion on the Methods and Measures of Reducing Rural Power Grid Loss," China Electric Power (Technology Edition), No. 10, 2012.

[2] M. Zhao and H. W. Tang, "Research of Reasonable Distribution Modes of Rural Power Grids,” Journal of China Agricultural University, No. 4, 2012.

[3] F. H. Li, T. M. Chen, F. S. Zheng, L. Z. Zhang and D. Q. Zhu, "Electromechanics," 2nd Edition, Beijing: Science Press, 1991, pp. 12-39 and 74-76.

[4] J. Liu, "Discussion and Analysis of Transformer Loss Calculation,” Equipment Manufacturing Technology, No. 11, 2012.

[5] J. S. Hu, “Transformer Economic Operation,” Beijing: China Electric Power Press, 1999, pp. 19-44.

[6] J. L. Xu, "Method to Reduce Power Transformer Loss," Electrotechnics Electric, No. 3, 2012. 